\title{
THE EFFECT OF LYSOLECITHIN ON THE ELECTRICAL RESISTANCE OF LECITHIN BILAYER MEMBRANES
}

\author{
Received 13 March 1967
}

Substantial evidence has been obtained in various laboratories for the participation of monoacyl phosphoglycerides in phospholipid metabolism of cell membranes (for reviews compare ${ }^{1}$ ) and ${ }^{2}$ )). Smalle concentrations of lysolecithin can be found in membranes of e.g. erythrocytes which normally are equipped with enzymes which acylate or hydrolyse these key intermediates. Such reactions may contribute to the dynamic character of the lipid core of the membrane and a local accumulation of lysolecithin may alter the permeability of such a region of the membrane.

In order to test this possibility use was made of lipid bilayer membranes which are known to have a number of properties which closely resemble those of natural membranes ${ }^{3-9}$ ).

The bilayer membranes were formed in a $1 \mathrm{~mm}$ aperture in a Teflon septum separating two compartments containing $0.1 \mathrm{M} \mathrm{NaCl}$. The membranes were prepared from solutions of lipid in decane of the following composition: (a) $1 \%$ egg lecithin, (b) $1 \%$ egg lecithin with various mole percentages of lysolecithin. The egg lecithin was isolated and purified according to established procedures, and found to give one spot on thin-layer chromatograms. The lecithin preparation was degraded with snake-venom phospholipase A so as to give (1-acyl)lysolecithin. The electrical resistance of the bilayer membranes was measured with an electrometer (Keithley, $610 \mathrm{~B}$ ) as principal unit of the electrical circuit. Use was made of reversible $\mathrm{Ag} / \mathrm{AgCl}$ electrodes, which did not introduce an emf of $>1 \mathrm{mV}$ into the circuit. All experiments were carried out at $25^{\circ} \mathrm{C}$.

The results are compiled in Fig. 1 and demonstrate the mean and standard deviation of the mean specific electrical resistance of the lecithin-lysolecithin bilayers. The values of the control lecithin bilayers (range $3 \times 10^{6}-1.4 \times 10^{7}$ $\Omega \mathrm{cm}^{2}$ ) are in fair agreement with those reported by Thompson ${ }^{7}$ ), but deviate from those recorded by Hanai et al. ${ }^{9}$ ). When the membranes were generated from solutions containing $0.5,1.0$ and 1.5 mole percent of lysolecithin no appreciable change of the electrical resistance was observed. However, at 


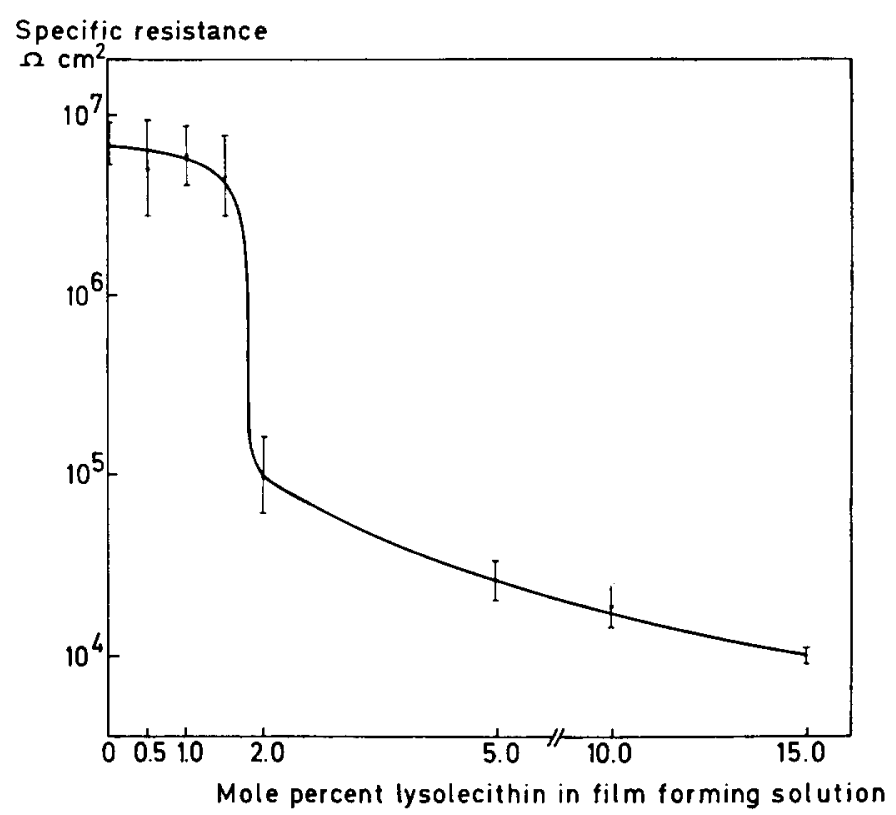

'Fig. 1. Electrical resistance of lipid bilayers generated with various mole percentages of lysolecithin (calculated on the amount of lecithin). The vertical bars indicate the standard deviation of the mean resistances.

2 mole percent of lysolecithin, there was a very significant decrease in the electrical resistance. The mean value for 9 membranes (range $1.2 \times 10^{4}-$ $1.9 \times 10^{5} \Omega \mathrm{cm}^{2}$ ) prepared in this manner was about 100 times lower than the mean value of the resistance of membranes composed of lecithin alone. A further increase of the lysolecithin concentration hardly brought about any further decrease of the electrical resistance. Stable bilayer films could be obtained from solutions containing 15 percent of lysolecithin but it was not possible to generate membranes from solutions containing about 20 percent of lysolecithin.

Although the actual composition of the artificial lipid bilayers is not known, the present experiments indicate that at a certain critical concentration lysolecithin may alter the permeability of the membrane significantly. The effects of sublytic concentrations of lysolecithin on the permeability of natural membranes need further investigations. It may be mentioned that current experiments of Reman ${ }^{10}$ ) on the lytic action of a series of synthetic lysolecithins demonstrated that lipid bilayers present a reasonable model system for studies on these agents.

The present investigations were carried out under the auspices of the 
Netherlands Foundation for Chemical Research (S.O.N.) and with financial aid from the Netherlands Organization for the Advancement of Pure Research (Z.W.O.).

Department of Biochemistry

H. VAN ZUTPHEN

The State University

L. L. M. van DeEnen

Utrecht, The Netherlands

\section{References}

1) L. L. M. van Deenen and G. H. de Haas, Ann. Rev. Biochem. 35 (1966) 157

2) W. E. M. Lands, Ann. Rev. Biochem. 34 (1965) 313

3) P. Mueller, D. O. Rudin, H. Ti Tien and W. C. Wescott, Nature 194 (1962) 979

4) P. Mueller and D. O. Rudin, J. Theoret. Biol. 4 (1963) 268

5) P. Mueller, D. O. Rudin, H. Ti Tien and W. C. Wescott, in: Recent progress in surface science, J. F. Danielli, et al. eds., Academic Press, New York, 1964

6) C. Huang, L. Wheeldon and T. E. Thompson, J. Mol. Biol. 8 (1964) 148

7) T. E. Thompson, in: Cellular membranes in development, M. Locke, ed., Academic Press, New York, 1964

8) J. Bielawski, T. E. Thompson and A. L. Lehninger, Biochem. Biophys. Res. Commun. 24 (1966) 948

9) T. Hanai, D. A. Haydon and J. Taylor, Proc. Roy. Soc. (London) A 281 (1964) 377

10) F. C. Reman and L. L. M. van Deenen, in preparation 